\title{
IMPLEMENTASI SMART SECURITY CAMERA PENDUKUNG SISTEM KEAMANAN LINGKUNGAN MANDIRI BERBASIS INTERNET OF THING (IoT)
}

\author{
Haryono Setiadi ${ }^{1}$, Rahmaniyah Dwi Astuti ${ }^{2}$, Rini Anggrainingsih ${ }^{3}$ \\ ${ }^{1}$ Fakultas MIPA Universitas Sebelas Maret \\ ${ }^{2}$ Fakultas MIPA Universitas Sebelas Maret \\ ${ }^{3}$ Fakultas Teknik Universitas Sebelas Maret \\ hsd@staff.uns.ac.id
}

\begin{abstract}
Abstrak
Secara geografis wilayah kelurahan Manahan terletak ditengah kota Surakarta. Wilayah tersebut sangat strategis karena terdapat beberapa bagunan/aset penting. Banyaknya aset penting tersebut selain membawa dampak positif bagi ekonomi warga sekitar juga membawa dampak negatif khususnya gangguan keamanan. Upaya menjaga keamanan masyarakat sebelumnya sudah dilakukan. Setiap RT terdapat sebuah sistem penjagaan keamanan yang dikenal dengan nama sistem keamanan lingkungan atau siskamling. Siskamling pada awalanya cukup efektif untuk menekan angka kriminalitas. Seiring berjalannya waktu banyak warga yang tidak bisa mengikuti sistem tersebut karena kesibukan. Penyelesaian masalah bagi warga dilakukan melalui dukungan teknologi dan dukungan manajemen. Upaya tersebut dilakukan secara aktif mengikutsertakan dan memberdayakan warga. Hasil dari kegiatan pengabdian berupa pemasangan alat yang membantu warga dalam mencegah terjadinya tindakan kejahatan yang mungkin terjadi pada lingkungan mereka. Alat smart security camera bisa diakses dimanapun oleh warga melalui smartphone. Implementasi ini memanfaatkan teknologi Internet of Thing (IoT). Hasil kegiatan lainnya adalah memberikan pengetahuan terkait people awareness agar warga lebih peduli terhadap keamanan lingkungan melalui sosialisasi modus-modus kejahatan yang mungkin terjadi dan bagaimana mencegahnya. Warga juga diberikan sosialisasi dan pendampingan lapangan terkait pemasangan dan pengoperasian smart security camera serta pelatihan terkait cara pengambilan alat bukti kejahatan berupa foto/video dari software.
\end{abstract}

Kata Kunci : cctv, smart security, IoT, keamanan mandiri

\section{PENDAHULUAN}

Dalam struktur Pemerintahan Daerah di tingkat Kabupaten/Kota, keberadaan Rukun Tetangga (RT) diatur dalam Peraturan Daerah (PERDA) di masing-masing daerah. RT merupakan organisasi masyarakat yang diakui Pemerintah Daerah setempat, khususnya dalam hal kegiatan administrasi kependudukan, kegiatan pembinaan lingkungan, pembinaan ketertiban masyarakat dan sebagainya. Pengurus RT di suatu lingkungan pemukiman masyarakat, ditetapkan berdasarkan pilihan masyarakat setempat (Layuk 2013). Pada kepengurusan RT, terdapat Seksi Keamanan yang dipimpin atau dikoordinir oleh seorang Kepala Seksi Keamanan. Tugas Kepala Seksi Keamanan antara lain membawahi para petugas Pertahanan Sipil (Hansip) atau Perlindungan Masyarakat (Linmas) dan warga setempat yang dilibatkan dalam kegiatan keamanan mandiri. Secara resmi, di suatu lingkungan pemukiman umum, pengelola dan penanggungjawab keamanan setempat adalah petugas Hansip atau Linmas.

Berdasarkan gambaran di atas, peran RT merupakan "ujung tombak" pemerintahan wilayah,

Teknologi Informasi dan Komunikasi 
karena RT inilah yang berhubungan langsung dengan masyarakat di lingkungan masing-masing. Artinya pengurus RT yang mengetahui berapa jumlah warga di lingkungannya, baik warga permanen maupun non permanen (warga yang indekost atau kontrak rumah). Berkaitan dengan keamanan lingkungan, fungsi Seksi Keamanan di lingkungan RT menjadi sangat penting. Namun hampir di banyak lingkungan pemukiman umum di kota besar seperti Surakarta, peran Seksi Keamanan di setiap kepengurusan RT tidak berjalan optimal. Pencurian masih kerap terjadi, perkelahian antarwarga sering berlangsung hingga menjadi perkelahian massal, pelanggaran hukum dan ketertiban masyarakat seperti pesta miras dan judi sering terjadi. Bahkan yang paling memprihatinkan, pihak Seksi Keamanan di lingkungan kepengurusan RT bisa tidak tahu kalau di lingkungannya terdapat kegiatan terorisme, peredaran narkoba, human trafficking, dan sebagainya.

Masalah keamanan lingkungan juga di alami oleh warga kelurahan Manahan, Banjarsari Surakarta. Secara geografis wilayah kelurahan Manahan terletak ditengah kota Surakarta dimana wilayah tersebut sangat strategis karena terdapat beberapa bagunan penting seperti lapangan olahraga berskala internasional Gelora Manahan, beberapa sekolah SMP/SMA (SMAN 4, SMKN 1, SMPN 1) serta kantor Polisi Resort Kota (Polresta) Surakarta. Peta kelurahan Manahan ditampilkan pada gambar 1.

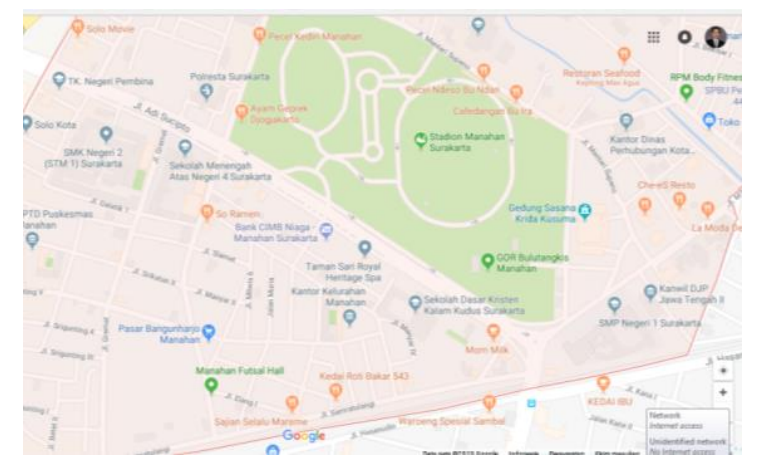

Gambar 1. Peta lokasi kelurahan Mahanan (sumber : Google map)

Berdasarkan data (https://esik.surakarta.go.id 2018) kelurahan Mahanan banyak berdiri rumah kost yang di sewakan kepada warga pendatang sejumlah 23\%. Banyaknya aset yang berada di kelurahan Manahan selain membawa dampak positif bagi ekonomi warga sekitar juga membawa dampak negatif khususnya bagi keamanan warga yang tinggal di sekitar kelurahan Manahan. Beberapa gangguan keamanan yang pernah terjadi di kelurahan Manahan misalnya ada kerusuhan yang terjadi antar suporter sepakbola yang bertanding di stadion gelora Manahan (https://kompas.com 2018), tidak kejahatan terorisme berupa tindakan bom bunuh diri di kantor Polresta Surakarta (https://www.bbc.com 2018) dan ganguan keamanan lainnya yang terjadi di kelurahan Manahan seperti tindakan kejahatan penjambretan (http://tribunnews.com 2018) dan lain sebagainya.

Upaya dalam menjaga keamanan masyarakat di kelurahan Mahanan Surakarta sudah dilakukan secara mandiri. Setiap RT yang ada terdapat sebuah sistem penjagaan keamanan yang dikenal dengan nama sistem keamanan lingkungan atau disingkat sebagai siskamling. Penjagaan keamanan lingkungan dengan siskamling pada awalnya cukup efektif untuk menekan angka kriminalitas. Namun, seiring berjalannya waktu banyak warga yang tidak bisa mengikuti sistem ini mengingat kesibukan yang semakin padat. Setelah siskamling dianggap kurang efektif untuk warga, diubahlah sistem keamanan masyarakat dengan menggunakan Linmas (Hansip) yang bertugas untuk menjaga keamanan lingkungan setiap malam. Cara ini efektif karena petugas Linmas biasanya bekerja menjadi petugas Linmas saja. Meskipun penjagaan yang dilakukan oleh Linmas sudah cukup baik, namun hal ini masih dirasa kurang oleh warga. Hal ini menyusul semakin tingginya angka kriminalitas di kelurahan Manahan.

Berdasarkan hasil diskusi awal yang dilakukan oleh Tim PKM UNS dengan warga Kelurahan Manahan didapatkan informasi bahwa selain pengamanan yang dilakukan oleh Linmas warga menyepakati untuk pemasangan alat dengan menggunakan teknologi Closed Circuit Television (CCTV) untuk membantu proses pengamanan. Sistem pengamanan mandiri dengan teknologi kamera CCTV ini diperlukan karena keterbatasan jumlah Linmas yang ada. Menurut warga masyarakat yang hadir pada pertemuan tersebut menyatakan bahwa teknologi CCTV bisa membantu 
untuk mencegah terjadinya tindak kriminal. Selain mencegah tindak kriminal teknologi CCTV juga bisa membantu dalam memberikan alat bukti jika terjadi telah terjadi tindakan kriminal seperti pencurian, penjambretan, terorisme dan tindakan kriminal lainnya di wilayah keluruhan Manahan.

Berdasarkan permasalahan-permasalahan yang telah diuraikan, perlu dilakukan upaya dan pencarian solusi, untuk mendukung warga dalam upaya penyelesaian masalah terkait keterbatasan Linmas dalam membatu keamanan warga. Solusi yang diambil adalah dengan mengimplementasikan hasil penelitian yang telah dilakukan Tim PKM UNS pada tahun 2018. Penelitian tersebut menghasilkan suatu alat yang diberi nama smart security camera.

Uraian permasalahan warga kelurahan Manahan, difokuskan dengan menggunakan diagram fishbone, agar teridentifikasi akar masalahnya. Hal ini yang akan menjadi dasar dalam merumuskan upaya-upaya penyelesaian masalah. Diagram fishbone permasalahan dan akarnya ditampilkan pada Gambar 1.

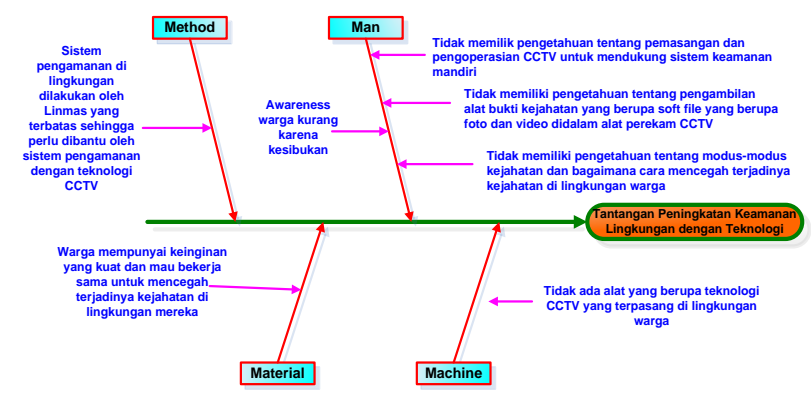

Gambar 1. Diagram Fishbone Permasalahan

\section{METODE}

Penyelesaian masalah bagi warga dilakukan melalui dukungan teknologi dan dukungan manajemen. Upaya tersebut dilakukan secara aktif mengikutsertakan dan memberdayakan warga kelurahan Manahan. Secara umum, metode dan tahapan dalam penyelesaian permasalahan mitra digambarkan pada Gambar 2.
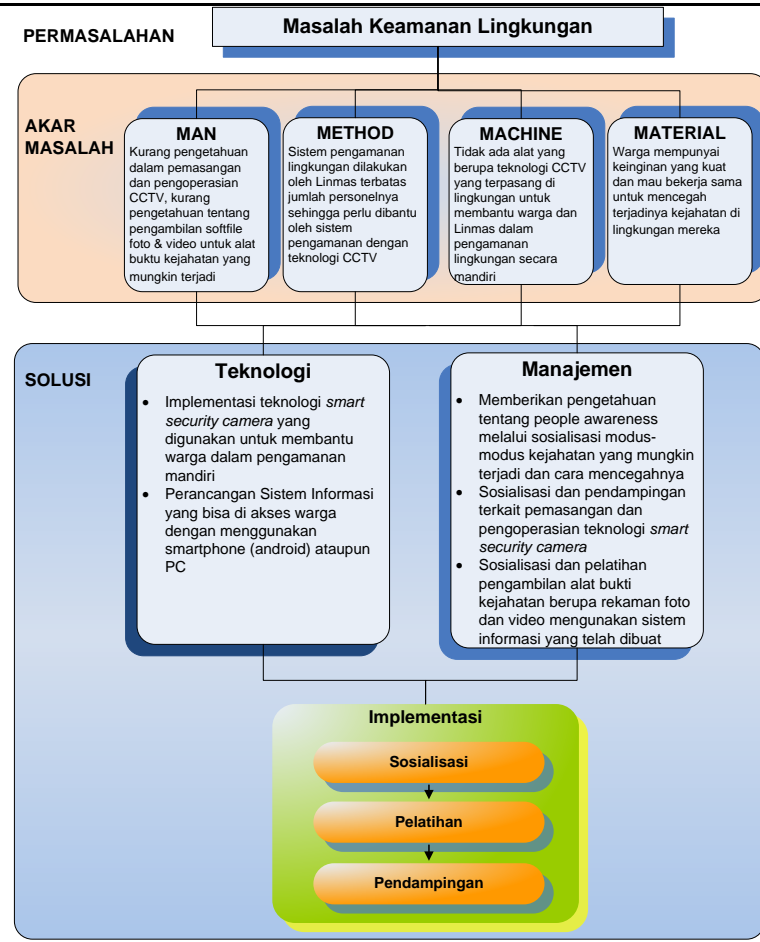

Gambar 2. Metode Penyelesaian Permasalahan Mitra

Secara spesifik, metode pelaksanaan kegiatan yang akan digunakan untuk menyelesaikan permasalahan bagi warga meliputi :

\section{Metode Pelaksanaan Kegiatan Terkait Permasalahan Teknologi}

Secara rinci, terdapat dua permasalahan yang dikaji oleh Tim PKM UNS dari sisi teknologi, yaitu terkait implementasi teknologi smart security camera yang digunakan untuk membantu warga dalam pengamanan mandiri, baik dari sisi penggunaan dan perawatannya. Selain itu Tim PKM UNS juga merancang Sistem Informasi yang bisa di akses oleh warga dengan menggunakan smartphone (android) ataupun PC.

Berkaitan dengan hal tersebut, berikut adalah solusi permasalahan yang dilakukan dengan : 1) Untuk membantu warga dalam hal sistem keamanan mandiri, diberikan solusi berupa implementasi teknologi smart security camera. Teknologi smart security camera ini merupakan hasil riset dan pengembangan yang dilakukan oleh TIM PKM UNS pada tahun 2018. Riset ini telah menghasilkan prototype alat teknologi smart

Teknologi Informasi dan Komunikasi 
security camera. Berdasarkan permasalahan warga yang telah digali oleh Tim PKM UNS, alat hasil rancangan ini dapat menjadi teknologi tepat guna yang dapat diimplementasikan untuk mendukung warga dalam membantu melaksanakan pengamanan mandiri. 2) Implementasi teknologi smart security camera akan menghasilkan soft file yang berupa rekaman foto atau video yang bisa digunakan sebagai alat bukti ketika terjadi tindak kejahatan di lingkungan warga. Untuk mengakses rekaman foto dan video tersebut digunakan aplikasi berbasis mobile phone.

\section{Metode Pelaksanaan Kegiatan Terkait Permasalahan Manajemen}

Implementasi teknologi di masyarakat, harus dibarengi dengan dukungan manajemen (pengelolaan) teknologi tersebut. Berkaitan dengan permasalahan manajemen ini, solusi yang diberikan adalah : memberikan pengetahuan kepada warga terkait dengan people awareness agar warga lebih peduli terhadap keamanan lingkungan melalui sosialisasi tentang modus-modus kejahatan yang mungkin terjadi dan bagaimana cara mencegah terjadinya kejahatan di lingkungan warga. Tim PKM UNS juga akan melakukan sosialisasi dan pendampingan lapangan terkait dengan pemasangan dan pengoperasian smart security camera untuk mendukung sistem keamanan mandiri. Selain itu Tim PKM UNS akan melakukan sosialisasi dan pelatihan terkait bagaimana cara pengambilan alat bukti kejahatan yang berupa soft file yang berupa foto dan video didalam alat smart security camera.

\section{Partisipasi Mitra}

Pendekatan yang dipergunakan dalam kegiatan ini adalah Participatory Rural Appraisal (PRA), dalam artian warga akan dilibatkan di seluruh tahap kegiatan. Keterlibatan warga pada setiap tahap kegiatan diuraikan sebagai berikut : 1) Warga terlibat dalam diskusi brainstorming perumusan permasalahan dan terlibat dalam diskusi bagiamana cara melakukan pengamanan mandiri dengan bantuan alat smart security camera. 2) Warga terlibat dalam penyempurnaan rancang bangun alat smart security camera. Warga juga akan terlibat langsung dalam tahap uji coba dan evaluasi alat smart security camera. 3) Pada tahap implementasi, warga terlibat dalam pemberian masukan (feedback) berkaitan dengan fungsionalitas alat smart security camera serta sistem informasi yang telah dibangun. Hal ini bertujuan agar alat hasil rancangan dapat diperbaiki dan dikembangkan lagi. 4) Pada kegiatan penyusunan modul pengoperasian alat smart security camera dan modul penggunaan sistem informasi, warga terlibat untuk memberikan masukan (feedback) terkait dengan konten modul. Hal ini dilakukan mengingat modul ini nantinya akan dipergunakan sebagai panduan warga, agar dapat menggunakan dan merawat alat secara mandiri dan berkelanjutan. 5) Warga terlibat menjadi koordinator peserta sosialisasi dan pelatihan aplikasi teknologi tepat guna yang dirancang dan dikembangkan oleh Tim PKM UNS.

Warga juga berperan dan berpartisipasi pada kegiatan ini dengan memberikan fasilitas tempat, sumber daya manusia. Selain itu, warga diharapkan dapat berperan menjadi agen untuk dapat menyebarkan ilmu pengetahuan dan teknologi (iptek) yang telah diberikan oleh tim PKM UNS kepada warga RT lain di kelurahan Manahan maupun wilayah kelurahan lainnya di Surakarta.

\section{HASIL DAN PEMBAHASAN}

Ipteks yang diaplikasikan kepada mitra terdiri dari teknologi tepat guna yang berupa rancang bangun teknologi tepat guna berupa smart security camera, penyusunan modul sosialisasi modusmodus kejahatan dan bagaimana cara pencehagannya, dan implementasi teknologi dengan kegiatan sosialisasi, pelatihan serta pendampingan alat smart security camera. Akvitas pengabdian masyarkat yang telah dilakukan diurakan sebagai berikut :

\section{Teknologi Smart Security Camera}

Untuk membantu warga dalam sistem keamanan mandiri, diberikan solusi berupa implementasi teknologi smart security camera. Pemasangan smart CCTV dilakukan di 8 titik di lingkungan Kelurahan Manahan. Untuk konektivitas antara alat perekam Digital Video Recorder (DVR) dengan smart security camera menggunakan teknologi Wireless Radio. Hal ini dikarenakan letak gegrafis lokasi mitra yang cukup

Teknologi Informasi dan Komunikasi 
jauh antara titik pemasangan smart security camera satu dengan yang lainnya. Agar smart security camera bisa diakses dimanapun oleh warga, implementasi ini memanfaatkan teknologi Internet of Thing (IoT). IoT merupakan suatu pengembangan internet yang sedang berjalan dimana benda-benda memiliki kemampuan komunikasi yang membuat mereka dapat mengirim dan menerima.(Shaik et al. 2017).

Berikut aktivitas kegiatan pemasangan smart cctv camera sudah implementasikan kepada mitra dipaparkan pada gambar 3 .

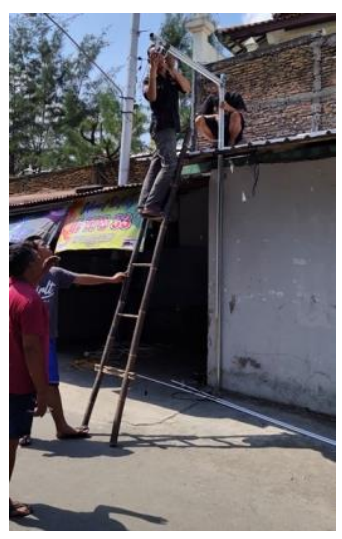

Gambar 3. Pemasangan alat smart CCTV Camera di lokasi mitra

\section{Sosialisasi Kepada Mitra}

Selain penerapan teknologi tepat guna smart security camera, warga juga membutuhkan dukungan dari sisi manajemen. Langkah awal yang dilakukan oleh Tim PKM UNS adalah memberikan pengetahuan kepada warga terkait dengan people awareness agar warga lebih peduli terhadap keamanan lingkungan melalui sosialisasi tentang modus-modus kejahatan yang mungkin terjadi dan bagaimana cara mencegah terjadinya kejahatan di lingkungan warga.

Tim PKM UNS juga melakukan sosialisasi dan pendampingan lapangan terkait dengan pemasangan, pengoperasian dan perawatan alat smart security camera untuk mendukung sistem keamanan mandiri. Foto kegiatan pada pada pelatihan tersebut dapat dilihat pada gambar 4 .
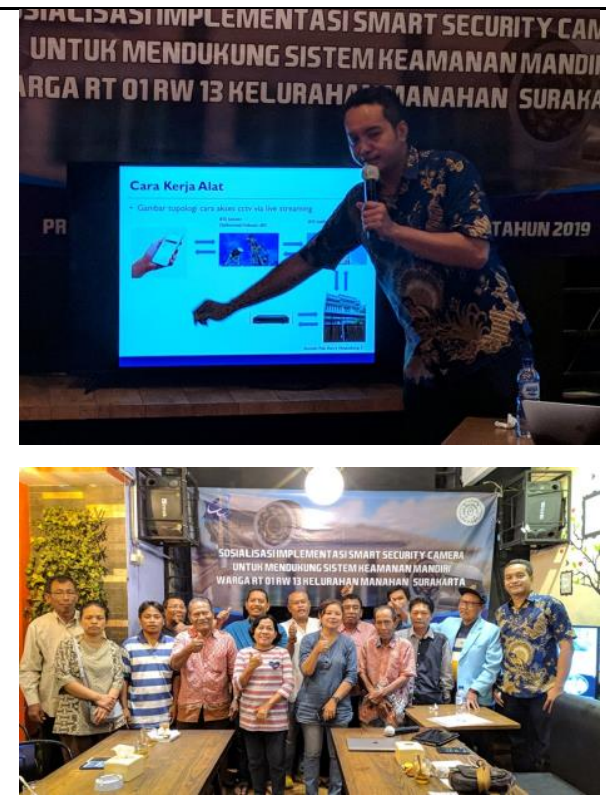

Gambar 4. Foto Kegiatan Sosialisasi Kepada Mitra

Langkah terakhir dalam tahapan pendekatan manajemen adalah melakukan sosialisasi dan pelatihan terkait bagaimana cara pengambilan alat bukti kejahatan yang berupa soft file dalam bentuk foto dan rekaman video didalam alat smart security camera dengan menggunakan sistem informasi berbasis mobile phone. Sofware berbasis mobile phone yang digunakan untuk melihat dan menampilkan gambar/rekaman camera ditampikan pada gambar 5 .

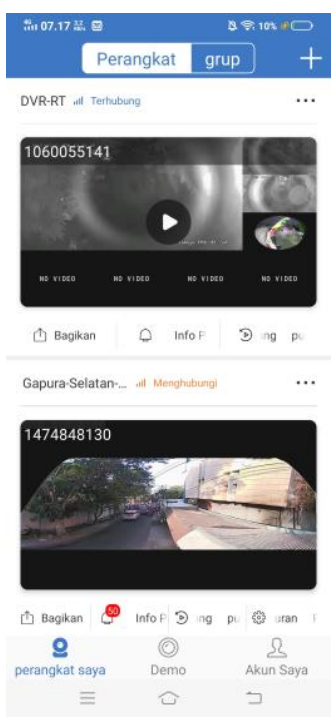

Gambar 5. Tampilan Sofware Yang digunakan Untuk Mengakses Smart CCTV melalui Handphone 


\section{KESIMPULAN}

Berdasarkan kegiatan Program Kemitraan Masyarakat (PKM) yang telah dilakukan oleh tim pengabdi, maka dibuat beberapa kesimpulan sebagai berikut : 1) Pada kegiatan pengabdian ini telah di implementasikan teknologi smart security camera dengan teknologi Internet of Thing untuk membatu warga dalam menjaga keamanan secara mandiri di lingkungan Kelurahan Mahanan Surakarta. 2) Smart CCTV camera yang berhasil di pasang sejumlah 8 titik pemasangan dengan jumlah kamera CCTV adalah 8 buah. Kamera yang terpasang sudah di ujicoba dan berhasil di akses oleh warga masyarakat melalui smartphone. 3) Untuk membekali warga masyarakat tim pengabdi memberikan pengetahuan kepada warga terkait dengan people awareness agar warga lebih peduli terhadap keamanan lingkungan melalui sosialisasi tentang modus-modus kejahatan yang mungkin terjadi dan bagaimana cara mencegah terjadinya kejahatan di lingkungan warga. 4) Tim PKM UNS juga melakukan sosialisasi dan pendampingan lapangan terkait dengan pemasangan, pengoperasian dan perawatan alat smart security camera. 5) Selain itu tim pengabdi juga memberikan sosialisasi dan pelatihan terkait bagaimana cara pengambilan alat bukti kejahatan yang berupa soft file dalam bentuk foto dan rekaman video didalam alat smart security camera .

\section{UCAPAN TERIMAKASIH}

Kegiatan program kemitraan masyarakat ini mendapatkan dukungan dana hibah Program Kemitraan Masyarakat (PKM) DIKTI tahun anggaran 2019.

\section{REFERENSI}

http://tribunnews.com. 2018. "Jadi Buron Hampir Sebulan, Pelaku Jambret Tas Ibu-Ibu Di Manahan Solo Dicokok Polisi." http://solo.tribunnews.com/2018/03/03/jadiburon-hampir-sebulan-pelaku-jambret-tas-ibuibu-di-manahan-solo-dicokok-polisi (June 22, 2018).

https://e-sik.surakarta.go.id. 2018. "Sistem Informasi Capaian Kesejahteraan Kota Surakarta." https://esik.surakarta.go.id/dlmangka/pbdt/indikator/33 72050/4/status-bangunan-tempat-tinggal.

https://kompas.com. 2018. "Tawuran Suporter Di Solo, 6 Orang Luka, 1 Kritis." https://regional.kompas.com/read/2013/09/04/ 2121019/Tawuran.Suporter.di.Solo.6.Orang.L uka.1.Kritis (July 5, 2018).

https://www.bbc.com. 2018. "Ledakan Bom Bunuh Diri Di Mapolres Solo." https://www.bbc.com/indonesia/berita_indone sia/2016/07/160705_indonesia_solo_bom.

Layuk, Merwy Rande. 2013. "Studi Tentang Kepemimpinan Ketua RT Di Desa Sebuntal Kecamatan Marangkayu Kabupaten Kutai Kartanegara." Ilmu Pemerintahan 1(1): 16578.

Shaik, Riaz, Narendra Kumar Gudapati, Nikhil Kumar Balijepalli, and Harshitha Raj Medida. 2017. "A Survey on Applications of Internet of Things." International Journal of Civil Engineering and Technology 8(12): 558-71. 